\title{
Development and Validation of a Reversed-Phase HPLC Method for the Estimation of Zolpidem in Bulk Drug and Tablets
}

\author{
E. Konoz, ${ }^{1}$ A. H. Mohsen Sarrafi, ${ }^{1}$ R. Abdolahnejad, ${ }^{2}$ and M. Bahrami-Zonoz ${ }^{1}$ \\ ${ }^{1}$ Department of Chemistry, Islamic Azad University, Central Tehran Branch, Tehran 13185-768, Iran \\ ${ }^{2}$ Loghman Pharmaceutical Co., P.O. Box 14155, Tehran 1443, Iran \\ Correspondence should be addressed to E. Konoz; konozelaheh@gmail.com
}

Received 24 June 2012; Accepted 2 September 2012

Academic Editor: Pranav S. Shrivastav

Copyright (c) 2013 E. Konoz et al. This is an open access article distributed under the Creative Commons Attribution License, which permits unrestricted use, distribution, and reproduction in any medium, provided the original work is properly cited.

\begin{abstract}
In the present study an isocratic reversed-phase high-performance liquid chromatography method was developed for the estimation of zolpidem in bulk drug and pharmaceutical dosage forms. The quantification was carried out on $\mathrm{C}_{18}$ columns. A mixture of acetonitrile-ammonium acetate $(\mathrm{pH}=8.0,0.02 \mathrm{M})(60: 40 \mathrm{v} / \mathrm{v})$ was used as the mobile phase, at flow rate of $1.0 \mathrm{~mL} / \mathrm{min}$ and the determination wavelength at $245 \mathrm{~nm}$. The retention time of zolpidem was found to be $3-5 \mathrm{~min}$. The validation of the proposed method was carried out for specificity, linearity, accuracy, precision, limit of detection, limit of quantification, and robustness. The linear dynamic range was from 2.5 to $30 \mu \mathrm{g} \mathrm{mL}^{-1}$. Regression equation was found to be $y=0.1416 x+0.0183$ with correlation coefficient $r=0.9996$. The percentage recovery obtained for zolpidem was greater than $96.5 \%$. Limit of quantification and limit of detection were found to be $2.5 \mu \mathrm{g} \mathrm{mL}^{-1}$ and $0.83 \mu \mathrm{g} \mathrm{mL} L^{-1}$, respectively. The developed method can be used for routine quality control analysis of zolpidem in tablet formulations.
\end{abstract}

\section{Introduction}

Zolpidem, 2-(4-methyl phenyl) N, N-6-trimethyl-imidazol $[1,2-\alpha]$ pyridine-3-acetamide, an imidazopyridine derivative, is a nonbenzodiazepine hypnotic indicated for the shortterm treatment of insomnia. Zolpidem (Figure 1) behaves as a sleep inducer without the muscle relaxant and anticonvulsant effects of the benzodiazepines. It improves sleep patients with insomnia.

The free base has a molecular weight of 307.4 , with the salt form (zolpidem hemitartrate) having a formula weight of 764.9. The salt has an appearance of a white to off-white powder, with a melting point of $193-197^{\circ} \mathrm{C}$. The tartrate salt is slightly soluble in water $\left(23 \mathrm{~g} / \mathrm{L}\right.$ at $\left.20^{\circ} \mathrm{C}\right)$, sparingly soluble in methanol, and practically insoluble in methylene chloride. The Ultraviolet (UV) spectrum of zolpidem in $0.1 \mathrm{~N} \mathrm{HCL}$ exhibits the $\lambda$ maximum of $294 \mathrm{~nm}[1-6]$.

Zolpidem is not a difficult drug to extract, detect over the therapeutic range, or detect at overdose levels. It has been measured in various biological specimens using a variety of different analytical techniques. Several analytical methods have been reported for quantification of zolpidem in human body fluids and organ samples including capillary electrophoresis (CE) [7], GC [8-10], HPLC [1, 3, 11-17], GC/MS [9, 18, 19], LC/MS [20], LC/MS/MS [21-23], and radioimmunoassay [24]. In the HPLC methods, the sensitivity of zolpidem is higher with fluorimetric detection than with UV detection [25]. Among these technologies, LC/MS and GC/MS are very expensive and are not often affordable for a common laboratory nowadays, and the derivative procedure made GC difficult to be a robust tool for monitoring zolpidem in many samples. Hence, it is a great selection to develop sufficiently selective and sensitive analytical method in terms of often used instruments such as HPLC-UV.

The main objective of the present work was to develop simple, fast, inexpensive, sensitive, and accurate method which could be applied to analyses of zolpidem in pure form and in pharmaceutical dosage form.

\section{Experimental}

2.1. Equipment. The HPLC apparatus was a Waters chromatographic system 1515 isocratic HPLC pump equipped with an injection valve $20 \mu \mathrm{L}$ and Waters 2487 UV-Visible 


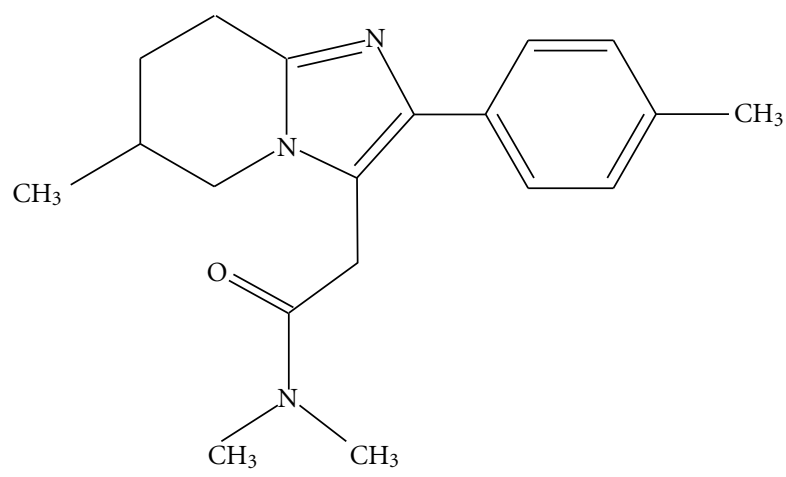

FIGURE 1: Structure of zolpidem.

detector. A reversed phase $\mathrm{C}_{18}$ column (Waters Xterra, $4.6 \times$ $250 \mathrm{~mm}$, particle size $5 \mu \mathrm{m}$ ) was used. The column oven temperature was set at $30 \pm 2^{\circ} \mathrm{C}$. Peak area integration was performed using Breez software version 3.30.

Samples were injected using $25 \mu \mathrm{L}$ Hamilton analytical syringe.

2.2. Chemicals and Reagents. HPLC grade acetonitrile, ammonium acetate (proanalysis), and orthophosphoric acid and ammonium solution 25\% (pro analysis) were purchased from Merck (Germany). Triple distilled water from the Milipore equipment was used to prepare all solutions. Authentic samples of zolpidem were obtained from Hexal pharmaceuticals (Germany).

The buffer solution was prepared by dissolving $1.54 \mathrm{~g}$ ammonium acetate in $1000 \mathrm{~mL}$ of triple distilled water and the $\mathrm{pH}$ was adjusted to 8 by addition of ammonium solution $25 \%$.

2.3. Preparation of Standard Solutions and Samples. An accurate weighted zolpidem reference standard was transferred to a $50 \mathrm{~mL}$ volumetric flask and dissolved in mobile phase to make solution of $20 \mu \mathrm{g} \mathrm{mL}^{-1}$. This solution contains about $0.02 \mathrm{mg}$ of zolpidem RS per $\mathrm{mL}$.

Twenty tablets were finely powdered and weighed; the average tablet weight was determined and weighed into $25 \mathrm{~mL}$ volumetric flask and dissolved in mobile phase. To dissolve it, the solution was sonicated into an ultrasonic bath for $5 \mathrm{~min}$, and transfer $2 \mathrm{~mL}$ of this solution to a $20 \mathrm{~mL}$ volumetric flask, dilute with mobile phase to volume, and $\operatorname{mix}$ [12]. Then this solution that contains $0.02 \mathrm{mg} / \mathrm{mL}$ of zolpidem was filtered through a $0.45 \mu \mathrm{m}$ PTFE syringe filter (Sartorius) and was used as sample solution.

For process control, $25 \mu \mathrm{L}$ of sample were pipetted accurately into $50 \mathrm{~mL}$ volumetric flasks and subsequently diluted to the desired volume with mobile phase. The solutions were sonicated into an ultrasonic bath for $1 \mathrm{~min}$ and filtered through a $0.45 \mu \mathrm{m}$ PTFE syringe filter (Sartorius) and then $20 \mu \mathrm{L}$ were injected into the HPLC apparatus.

2.4. Calibration Procedure. The calibration curve was obtained with six concentrations of standard solution 2.5

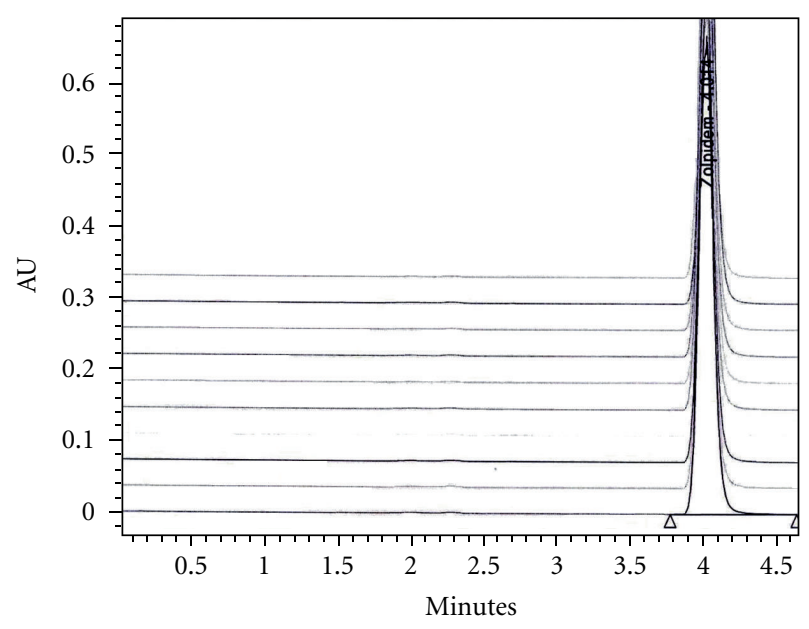

FIgURE 2: Chromatograms of a solution containing zolpidem at a concentration of $20 \mu \mathrm{g} \mathrm{mL}^{-1}$ at the described chromatographic conditions.

to $30 \mu \mathrm{g} \mathrm{mL}^{-1}$; solutions were prepared in triplicate. The linearity was evaluated by linear regression analysis, which was calculated by the least square regression method. Before injection of solution, the column was equilibrated for $60 \mathrm{~min}$ with mobile phase flowing through the system. Three determinations were carried out for each solution. Peak area was recorded for all the solutions. The correlation graph was constructed by plotting the peak area obtained at the optimum wavelength of detection versus the injected amounts.

2.5. Chromatographic Conditions. The mobile phase was a mixture of acetonitrile/ammonium acetate buffer $0.02 \mathrm{M}$, $\mathrm{pH}=8,(60: 40 \mathrm{v} / \mathrm{v})$. The flow rate was $1 \mathrm{~mL} \mathrm{~min}^{-1}$. The UV detector wavelength was set at $245 \mathrm{~nm}$ and the column oven temperature was set at $30 \pm 2^{\circ} \mathrm{C}$.

\section{Results and Discussion}

3.1. System Suitability. The chromatographic separation, as explained above, was carried out with HPLC to evaluate the chromatographic parameters including retention factor $(k)$, asymmetry of the peak, and tailing factor. Figure 2 showed that no interference peaks were observed in the representative chromatogram. The retention factor $(k)$ of the zolpidem peak, the tailing factor parameter, and USP Plate Count were $4.4,1.1$ and $>7500$, respectively. It was concluded that the developed method is the optimum according to the studied parameters. The resulted retention factor was within the range of accepted value $(>2)$. The tailing factor to be controlled was within the limits established by these guidelines.

It can be seen in Figure 2, which shows the chromatogram obtained according to these optimized conditions, good peak asymmetry in a reasonable run time, that is, $4 \mathrm{~min}$. Alternatively, different gradient elution programs using acetonitrile as organic modifier were tested and used 
TABLE 1: Accuracy for zolpidem.

\begin{tabular}{lccc}
\hline $\begin{array}{l}\text { Nominal concentration } \\
\left(\mu \mathrm{g} \mathrm{mL}^{-1}\right)\end{array}$ & $\begin{array}{c}\text { Mean measured } \\
\text { concentration } \\
\left(\mu \mathrm{g} \mathrm{mL}^{-1}\right)^{\mathrm{a}}\end{array}$ & $\begin{array}{c}\text { Recovery } \\
(\%)^{\mathrm{a}}\end{array}$ & $\begin{array}{c}\text { RSD } \\
(\%)^{\mathrm{b}}\end{array}$ \\
\hline 10 & $9.67( \pm 0.3)$ & 96.45 & 0.07 \\
20 & $19.6( \pm 0.4)$ & 98.00 & 1.00 \\
30 & $31.3( \pm 0.2)$ & 104.3 & 0.30 \\
\hline Mean & & 99.60 & 0.46 \\
\hline
\end{tabular}

a Mean of six determinations.

${ }^{\mathrm{b}} \mathrm{RSD}$ : relative standard deviation.

photodiode array detector was published [6]. The HPLC analyses were performed using an isocratic mobile phase consisting methanol-acetonitrileand $26 \mathrm{mM}$ sodium acetate buffer $(\mathrm{pH} 2.0)$ containing $0.26 \mathrm{mM}$ tetrabutyl ammonium phosphate $(13: 10: 77 \mathrm{v} / \mathrm{v} / \mathrm{v})$ and flow rate was set at $0.3 \mathrm{~mL} \mathrm{~min}^{-1}$ in another published paper [12].

Therefore, the main objective of the present work can be applied properly to its intended purpose, and compared with past publishedpapers HPLC methods are very easy, simple, fast, and inexpensive.

3.2. Stability of the Solution. Results obtained in the study of stocks solutions of zolpidem in mobile phase were found to be stable for 5 days $(120 \mathrm{~h})$, when kept in refrigerator.

\section{Method Validation}

4.1. Specificity. Specificity described as the ability of a method to discriminate the analyte from all potential interfering substances was evaluated by preparing the analytical placebo and it was confirmed that the signal measured was caused only by the analytes. A solution of an analytical placebo (containing all the ingredients of the formulation except the analyte) was prepared according to the sample preparation procedure and injected to HPLC. A mixture of the inactive ingredients (placebo) before (Figure 3(a)) and after being spiked with standards (Figure 3(b)), standard solutions (Figure 3(c)), and the commercial pharmaceutical preparations including zolpidem (Figure 3(d)) were analyzed by the proposed method, to identify the interference by these recipients. The obtained results show that the peak of analytes was pure and recipients in the formulation did not interfere with the analyte.

4.2. Accuracy and Recovery Studies. Accuracy was studied using three different solutions, containing 10,20, and $30 \mu \mathrm{g} \mathrm{mL}^{-1}$ of zolpidem. Recovery data were reported in Table 1. The obtained values were within the range of 96.45 and $104.3 \%$.

4.3. Precision. The precision of an analytical procedure expresses the closeness of agreement between a series of measurement obtained from multiple sampling of the same homogenous sample under the prescribed conditions. The system precision is a measure of the method variability that can be expected for a given analyst performing the analysis and was determined by performing six replicate analyses of the same working solution. The relative standard deviation (RSD) obtained for zolpidem was 0.46 (Table 1).

The intra- and interday variability or precision of data is summarized in Table 2. The intraday precision of the developed LC method was determined by preparing the tablet samples of the same batch in ten determinations with three concentrations, expressed as a parentage of the label claim, which were used to evaluate the method precision. The intraday precision was also determined by assaying the tablets in triplicate per day for consecutive 3 days. The results indicated the good precision of the developed method (Table 2).

4.4. Linearity. The linearity of the proposed method was estimated by regression analysis at six concentration levels in the range of $2.5-30 \mu \mathrm{g} \mathrm{mL}^{-1}$. The slope and intercept of calibration curves are shown in Table 4 . The calibration curve was obtained by applying linear regression model based on the least square method.

4.5. Limit of Detection (LOD) and Limit of Quantification (LOQ). LOD and LOQ of zolpidem were determined by calibration curve method [26]. Solutions of zolpidem were prepared in the range of $2.5-30 \mu \mathrm{g} \mathrm{mL}^{-1}$ and injected in triplicate. Average peak area of three analyses were plotted against concentration. The LOD and LOQ were calculated using the following equations:

$$
\begin{aligned}
\mathrm{LOD} & =\frac{3.3 \times S_{a}}{b}, \\
\mathrm{LOQ} & =\frac{10.0 \times S_{a}}{b},
\end{aligned}
$$

where $S_{a}$ is residual variance due to regression; $b$ is slope. The obtained LOD and LOQ for zolpidem were 0.83 and $2.5 \mu \mathrm{g} \mathrm{mL}^{-1}$, respectively (Table 3 ).

4.6. Robustness. Robustness relates to the capacity of the method to remain unaffected by small but deliberate variations introduced into the method parameters. Several experimental parameters as changes of $\mathrm{pH}$ of the mobile phase, flow rate, percentage of acetonitrile in the mobile phase, column oven temperature, and detection wavelength were varied around the value set in the method to reflect changes in different test environments. Analysis was carried out in triplicate and only one parameter was changed in the experiments at a time. The degree of reproducibility of the results obtained as a result of small deliberate variations in the method parameters has proven that the method is robust (Table 4).

4.7. Analysis of Pharmaceutical Preparations. Developed and validated method was applied to determination of zolpidem in ten different pharmaceutical preparations. These preparations have the same amount of zolpidem $(5 \mathrm{mg})$. Each pharmaceutical preparation was analyzed by performing eight independent determinations. Satisfactory results were 
TABLE 2: Intra- and interday assay precision data $(n=10)$.

\begin{tabular}{|c|c|c|c|c|c|c|}
\hline \multirow{3}{*}{$\begin{array}{l}\text { Standard concentration } \\
\left(\mu \mathrm{g} \mathrm{mL}^{-1}\right)\end{array}$} & \multicolumn{6}{|c|}{ Measured Concentration } \\
\hline & \multicolumn{3}{|c|}{ Intraday } & \multicolumn{3}{|c|}{ Interday } \\
\hline & $\mathrm{mg} / \mathrm{tab}$ & Recovery (\%) & RSD (\%) & $\mathrm{mg} / \mathrm{tab}$ & Recovery (\%) & RSD (\%) \\
\hline 10.8 & 4.93 & 98.7 & 0.2 & 4.95 & 99.05 & 1.6 \\
\hline 21.6 & 5.13 & 102.7 & 0.3 & 5.12 & 102.50 & 1.5 \\
\hline 32.4 & 5.18 & 103.6 & 0.3 & 5.09 & 101.80 & 0.8 \\
\hline
\end{tabular}

Nominal concentration of sample solution was $20 \mu \mathrm{g} \mathrm{mL} \mathrm{L}^{-1}$ and tablets were $5 \mathrm{mg}$.

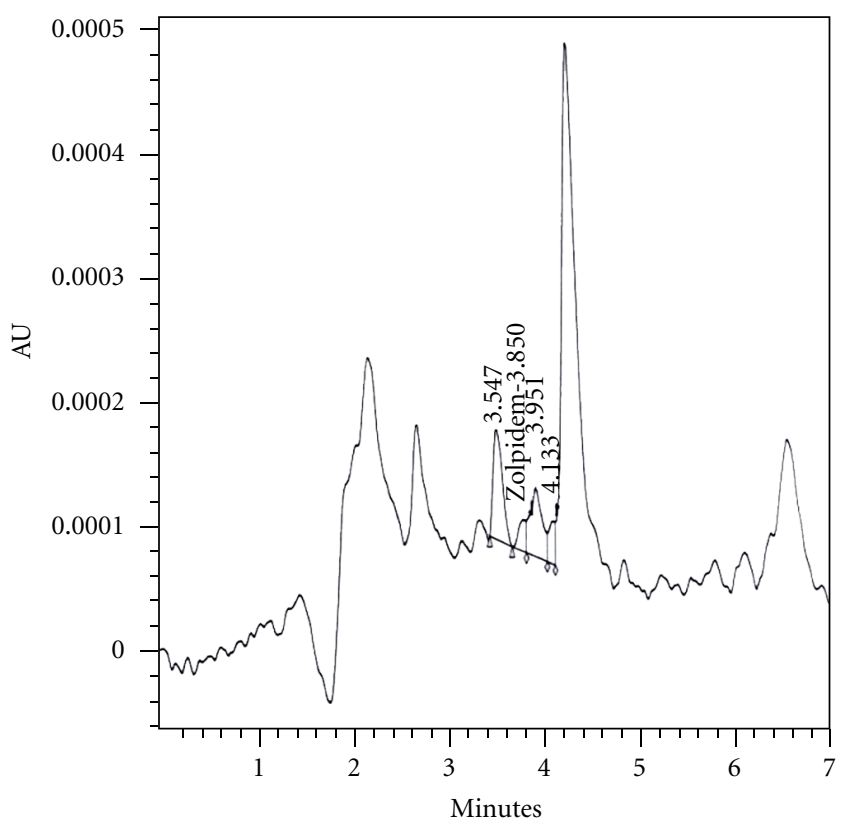

(a)

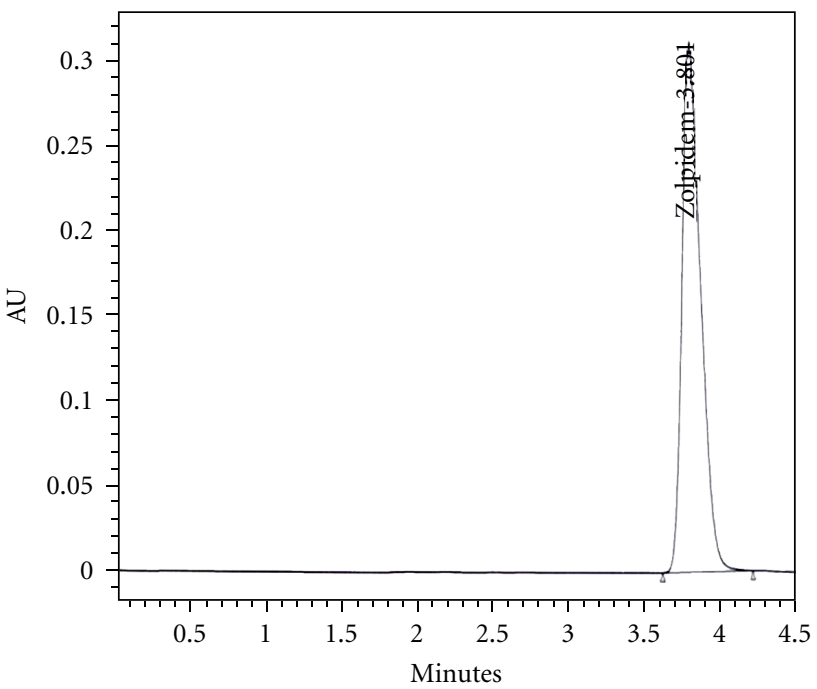

(c)

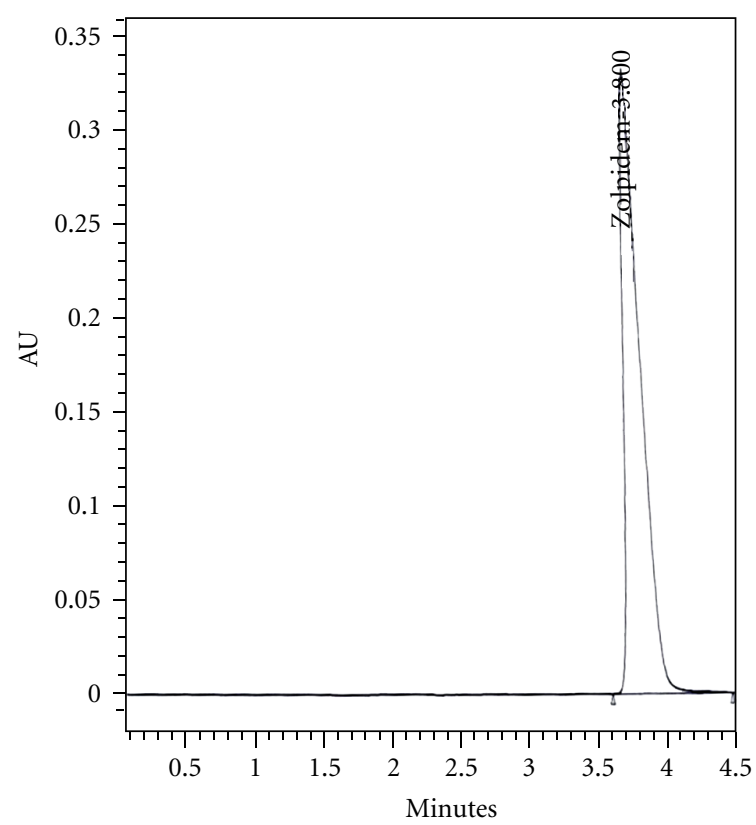

(b)

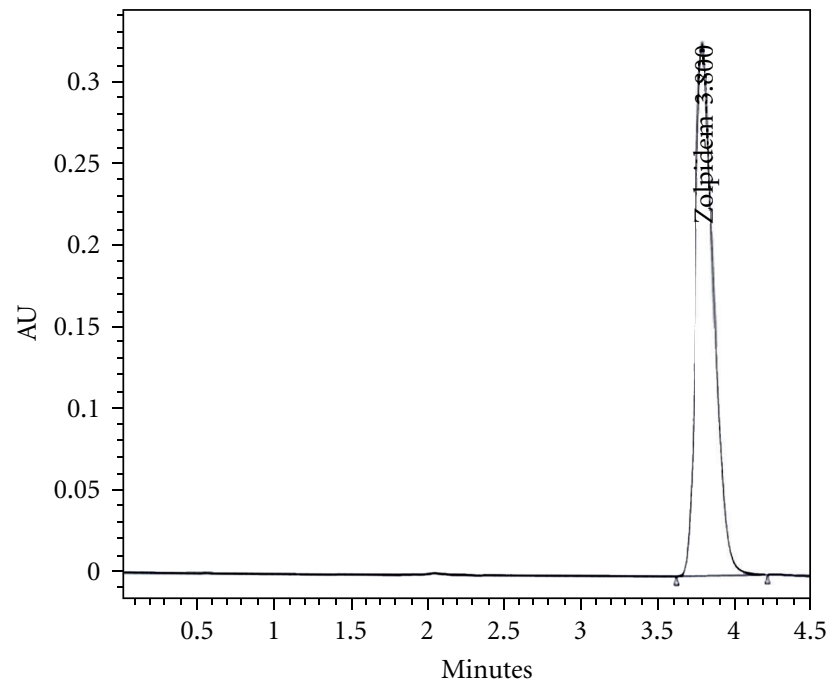

(d)

FIGURE 3: The chromatograms of (a) tablet excipients (placebo), (b) tablet excipients after being spiked with standard, (c) standard solutions, and (d) commercial pharmaceutical preparation at the described chromatographic conditions. 
TABLE 3: Results of the data analysis for the quantitative determination of zolpidem by the proposed method.

\begin{tabular}{lc}
\hline Statistical parameter & HPLC \\
\hline Concentration range $\left(\mu \mathrm{g} \mathrm{mL}^{-1}\right)$ & $2.5-30$ \\
Regression equation & $y=0.1416 x+0.0183$ \\
Correlation coefficient $(r)$ & 0.9996 \\
Standard error on estimation $\left(S_{e}\right)$ & 0.049 \\
Standard deviation on slope $\left(S_{b}\right)$ & 0.00199 \\
Standard deviation on intercept $\left(S_{a}\right)$ & 0.0356 \\
Limit of detection $(\mathrm{LOD})\left(\mu \mathrm{g} \mathrm{mL} \mathrm{mL}^{-1}\right)$ & 0.83 \\
Limit of quantification $(\mathrm{LOQ})\left(\mu \mathrm{g} \mathrm{mL}^{-1}\right)$ & 2.5 \\
\hline
\end{tabular}

TABLE 4: Result of robustness study.

\begin{tabular}{lccc}
\hline Factor & Level & Mean & \% RSD \\
\hline \multirow{3}{*}{ pH of mobile phase } & 6.3 & 5.03 & 0.4 \\
& 8.0 & 5.01 & 0.8 \\
& 9.67 & 5.06 & 0.3 \\
\hline \multirow{2}{*}{ Flow rate $(\mathrm{mL} / \mathrm{min})$} & 0.5 & 5.10 & 0.6 \\
& 1.0 & 5.15 & 0.8 \\
& 1.5 & 5.12 & 0.2 \\
Column oven temperature $\left({ }^{\circ} \mathrm{C}\right)$ & 2.0 & 5.16 & 0.4 \\
\hline \multirow{2}{*}{ \% acetonitrile } & 25 & 5.03 & 0.8 \\
& 45 & 5.07 & 0.1 \\
& 45 & 5.10 & 0.4 \\
\hline \multirow{2}{*}{ Detection wavelength $(\mathrm{nm})$} & $(55 / 45)$ & 4.98 & 0.5 \\
& $(60 / 40)$ & 5.01 & 0.3 \\
\hline
\end{tabular}

obtained for each compound and were found to be in agreement with label claims (Table 5).

The proposed method was compared to the UV spectrophotometric method, to verify the results obtained from HPLC. A calibration equation was obtained in the concentration range $2-10 \mu \mathrm{g} \mathrm{mL}^{-1}$ at a wavelength of $245 \mathrm{~nm}$ by using methanol as blank. The relation between absorbance $(A)$ and concentration of zolpidem $(C)$ was $[y=0.1231 x-$ $0.0004, r=0.9996]$. The tablet dosage from analysis results was found to be $5.37 \pm 0.07$ (mean $\pm \mathrm{SD} ; n=6$ ) by UV spectrophotometric method. High reproducibility and insignificant difference between the two methods were obtained at the 0.05 probability level according to $t$ - and $F$-tests.

\section{Conclusions}

A simple, specific, linear, precise, and accurate RP-HPLC method has been developed and validated for quantitative determination of zolpidem in tablet formation. The method is very simple and specific for zolpidem (chromatograms show no other peaks) and excipient peaks with total run time of $5 \mathrm{~min}$, which make it especially suitable for routine quality control analysis work.
TABLE 5: Data from the analysis of commercial tablets by HPLC and UV method.

\begin{tabular}{lcccc}
\hline \multirow{2}{*}{ Company } & \multicolumn{2}{c}{ HPLC method } & \multicolumn{2}{c}{ UV method } \\
& mg/tab & Recovery \% & mg/tab & Recovery \% \\
\hline Hexal $^{\mathrm{a}}$ & 10.08 & 100.7 & 10.10 & 100.9 \\
Sandoz $^{\mathrm{a}}$ & 10.60 & 105.5 & 10.16 & 101.7 \\
Aboreyhan $^{\mathrm{b}}$ & 5.06 & 101.3 & 5.30 & 105.6 \\
Amin $^{\mathrm{b}}$ & 5.23 & 104.6 & 5.20 & 104.0 \\
Bakhtar bio shimmy $^{\mathrm{b}}$ & 4.93 & 98.7 & 5.30 & 105.6 \\
Jalinous $^{\mathrm{b}}$ & 4.94 & 98.8 & 5.07 & 101.5 \\
kish medi pharma $^{\mathrm{b}}$ & 5.10 & 102.2 & 5.12 & 102.6 \\
kimidaro $^{\mathrm{b}}$ & 4.99 & 99.9 & 5.50 & 109.9 \\
loghman $^{\mathrm{b}}$ & 5.50 & 109.7 & 5.47 & 109.5 \\
Osvah $^{\mathrm{b}}$ & 5.20 & 103.3 & 4.94 & 98.8 \\
\hline
\end{tabular}

Nominal concentration of each company was $20 \mu \mathrm{g} \mathrm{mL}^{-1}$.

${ }^{a}$ Nominal mg per tab of these companies (Germany) was $10 \mathrm{mg}$.

${ }^{\mathrm{b}}$ Nominal mg per tab of these companies was $5 \mathrm{mg}$.

\section{Acknowledgments}

The authors would like to thank their deputy of Loghman pharmaceutical company, for providing pure drug reference sample and supporting this work. The authors also acknowledge M. Moeinipour for her helpful discussion.

\section{References}

[1] P. R. Ring and J. M. Bostick, "Validation of a method for the determination of zolpidem in human plasma using LC with fluorescence detection," Journal of Pharmaceutical and Biomedical Analysis, vol. 22, no. 3, pp. 495-504, 2000.

[2] R. V. S. Nirogi, V. N. Kandikere, and K. Mudigonda, "Quantitation of zopiclone and desmethylzopiclone in human plasma by high-performance liquid chromatography using fluorescence detection," Biomedical Chromatography, vol. 20, no. 8, pp. 794-799, 2006.

[3] P. Guinebault, C. Dubruc, P. Hermann, and J. P. Thénot, "Highperformance liquid chromatographic determination of zolpidem, a new sleep inducer, in biological fluids with fluorimetric detection," Journal of Chromatography B, vol. 383, pp. 206-211, 1986.

[4] J. Bhatt, A. Jangid, R. Shetty et al., "Quantification of zolpidem in human plasma by liquid chromatography-electrospray ionization tandem mass spectrometry," Biomedical Chromatography, vol. 20, no. 8, pp. 736-742, 2006.

[5] R. V. S. Nirogi, V. N. Kandikere, W. Shrivasthava, and K. Mudigonda, "Quantification of zolpidem in human plasma by high-performance liquid chromatography with flourescence detection," Biomedical Chromatography, vol. 20, no. 10, pp. 1103-1108, 2006.

[6] L. Laviana, C. Mangas, F. Fernández-Marí, M. Bayod, and D. Blanco, "Determination and in-process control of zolpidem synthesis by high-performance liquid chromatography," Journal of Pharmaceutical and Biomedical Analysis, vol. 36, no. 4, pp. 925-928, 2004.

[7] G. L. Hempe and G. Blanschke, "Direct determination of zolpidem and its main metabolites in urine using capillary electrophoresis with laser-induced fluorescence detection," Journal of Chromatography B, vol. 675, no. 1, pp. 131-137, 1996. 
[8] J. E. Meeker, C. W. Som, E. C. Macapagal, and P. A. Benson, "Zolpidem tissue concentrations in a multiple drug related death involving Ambien," Journal of Analytical Toxicology, vol. 19, no. 6, pp. 531-534, 1995.

[9] F. Stanke, N. Jourdil, J. Bessard, and G. Bessard, "Simultaneous determination of zolpidem and zopiclone in human plasma by gas chromatography-nitrogen-phosphorus detection," Journal of Chromatography B, vol. 675, no. 1, pp. 43-51, 1996.

[10] Y. Gaillard, J. P. Gay-Montchamp, and M. Ollagnier, "Simultaneous screening and quantitation of alpidem, zolpidem, buspirone and benzodiazepines by dual-channel gas chromatography using electron-capture and nitrogen-phosphorus detection after solid-phase extraction," Journal of Chromatography B, vol. 622, no. 2, pp. 197-208, 1993.

[11] A. L. B. Durol and D. J. Greenblatt, "Analysis of zolpidem in human plasma by high-performance liquid chromatography with fluorescence detection: application to single-dose pharmacokinetic studies," Journal of Analytical Toxicology, vol. 21, no. 5, pp. 388-392, 1997.

[12] Q. Wang, L. Sun, and C. E. Lau, "Determination of zolpidem in serum microsamples by high-performance liquid chromatography and its application to pharmacokinetics in rats," Journal of Chromatography B, vol. 734, no. 2, pp. 299-305, 1999.

[13] P. Ptacek, J. Macek, and J. Klima, "Rapid and simple method for the determination of zolpidem in human plasma by highperformance liquid chromatography," Journal of Chromatography B, vol. 694, no. 2, pp. 409-413, 1997.

[14] A. Tracqui, P. Kintz, and P. Mangin, "High-performance liquid chromatographic assay with diode-array detection for toxicological screening of zopiclone, zolpidem, suriclone and alpidem in human plasma," Journal of Chromatography B, vol. 616, no. 1, pp. 95-103, 1993.

[15] G. Debailleul, F. A. Khalil, and P. Lheureux, "HPLC quantification of zolpidem and prothipendyl in a voluntary intoxication," Journal of Analytical Toxicology, vol. 15, no. 1, pp. 35-37, 1991.

[16] D. Debruyne, J. Lacotte, B. Hurault de Ligny, and M. Moulin, "Determination of zolpidem and zopiclone in serum by capillary column gas chromatography," Journal of Pharmaceutical Sciences, vol. 80, no. 1, pp. 71-74, 1991.

[17] V. Ascalone, L. Flaminio, P. Guinebault, J. P. Thénot, and P. L. Morselli, "Determination of zolpidem, a new sleep-inducing agent, and its metabolites in biological fluids: pharmacokinetics, drug metabolism and overdosing investigations in humans," Journal of Chromatography B, vol. 581, no. 2, pp. 237-250, 1992.

[18] M. Lichtenwalner and R. Tully, "A fatality involving zolpidem," Journal of Analytical Toxicology, vol. 21, no. 7, pp. 567-569, 1997.

[19] T. Keller, A. Schneider, and E. Tutsch-Bauer, "GC/MS determination of zolpidem in postmortem specimens in a voluntary intoxication," Forensic Science International, vol. 106, no. 2, pp. 103-108, 1999.

[20] C. Kratzsch, O. Tenberken, F. T. Peters, A. A. Weber, T. Kraemer, and H. H. Maurer, "Screening, library-assisted identification and validated quantification of 23 benzodiazepines, flumazenil, zaleplone, zolpidem and zopiclone in plasma by liquid chromatography/mass spectrometry with atmospheric pressure chemical ionization," Journal of Mass Spectrometry, vol. 39, no. 8, pp. 856-872, 2004.

[21] P. Kintz, M. Villain, and B. Ludes, "Testing for the undetectable in drug-facilitated sexual assault using hair analyzed by tandem mass spectrometry as evidence," Therapeutic Drug Monitoring, vol. 26, no. 2, pp. 211-214, 2004.

[22] P. Kintz, M. Villain, M. Conchiero, and V. Cirimele, "Screening and confirmatory method for benzodiazepines and hypnotics in oral fluid by LC-MS/MS," Forensic Science International, vol. 150, no. 2, pp. 213-220, 2005.

[23] S. C. Hopkins, J. B. Nofsinger, M. S. Allen, P. Koch, and M. A. Varney, "In vivo saturation binding of GABA-A receptor ligands to estimate receptor occupancy using liquid chromatography/tandem mass spectrometry," Biopharmaceutics and Drug Disposition, vol. 30, no. 1, pp. 9-20, 2009.

[24] I. De Clerck and P. Daenens, "Development of a radioimmunoassay for the determination of zolpidem in biological samples," Analyst, vol. 122, no. 10, pp. 1119-1124, 1997.

[25] F. J. Flores-Murrieta, C. Hoyo-Vadillo, E. Hong, and G. Castañeda-Hernandez, "Assay of ambroxol in human plasma by high-performance liquid chromatography with amperometric detection," Journal of Chromatography B, vol. 490, pp. 464-469, 1989.

[26] D. M. Bliesner, Validating Chromatographic Methods, John Wiley \& Sons, New York, NY, USA, 2006. 

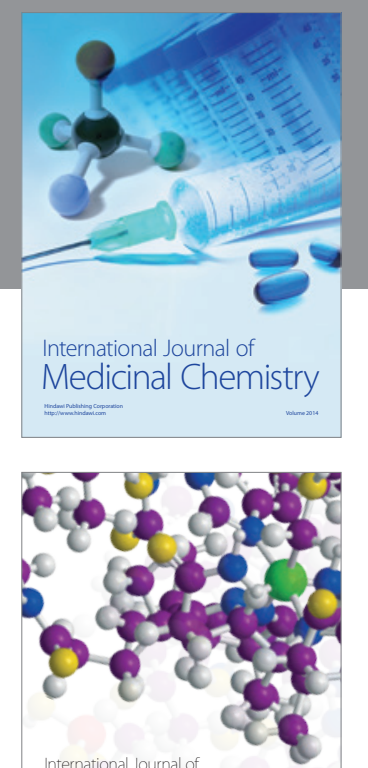

\section{Carbohydrate} Chemistry

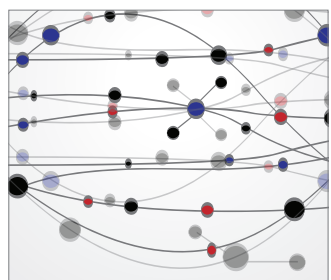

The Scientific World Journal
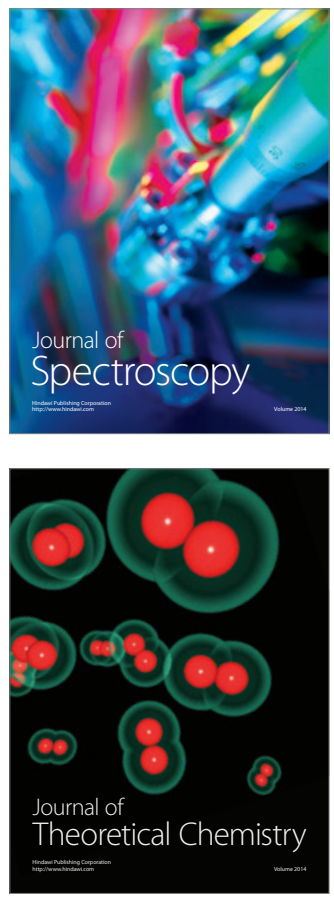
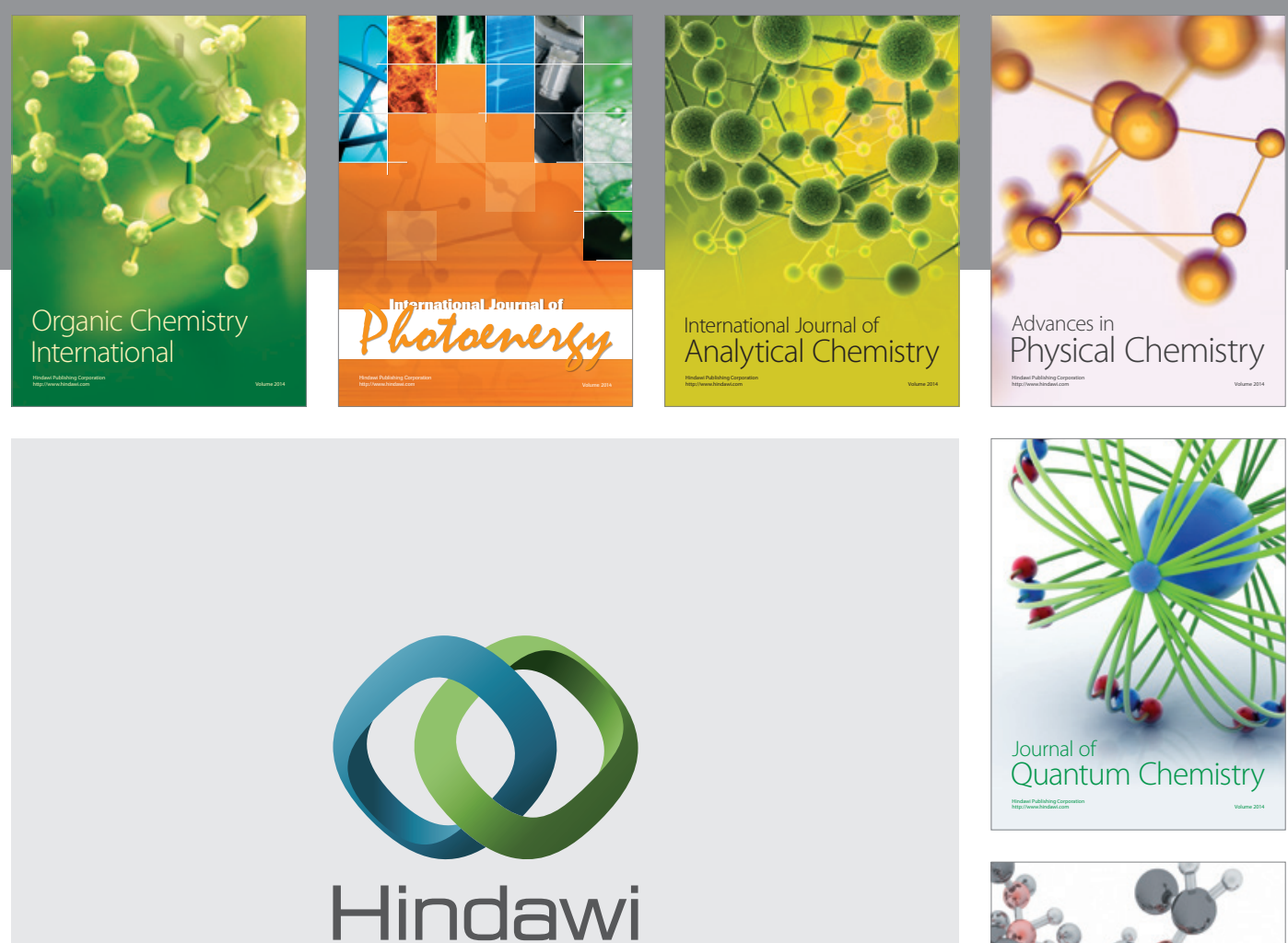

Submit your manuscripts at

http://www.hindawi.com

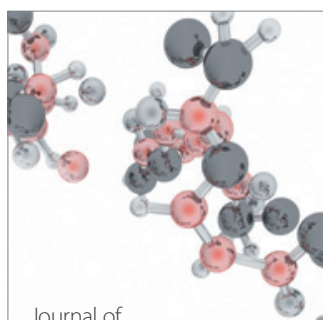

Analytical Methods

in Chemistry

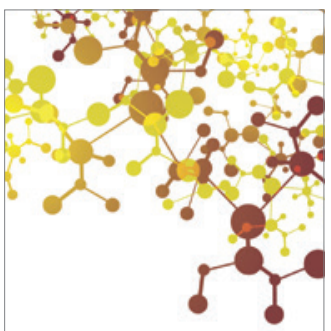

Journal of

Applied Chemistry

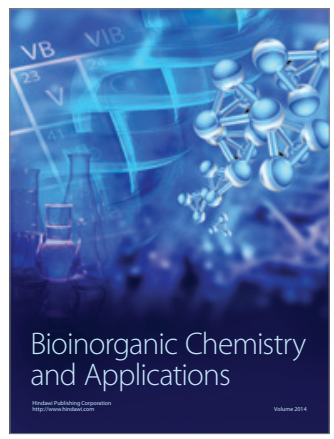

Inorganic Chemistry
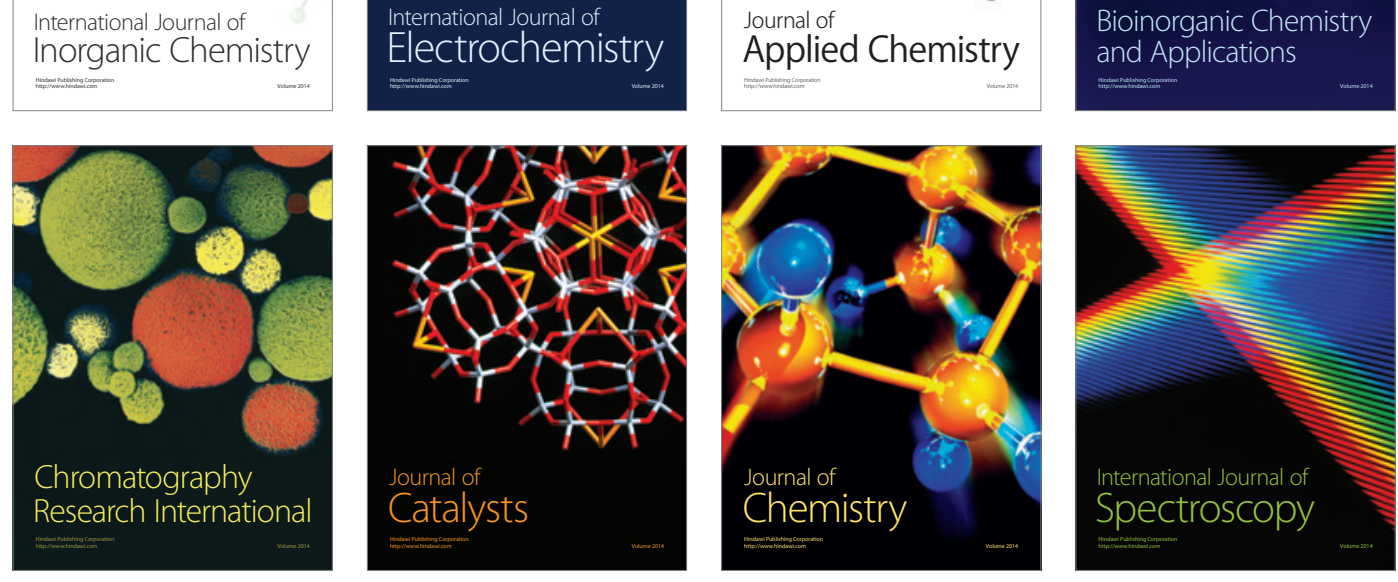